Marketing in Asia Group

Asian Journal of Business Research

Volume 9 Issue 1, 2019

ISSN 2463-4522 e-ISSN 1778-8933

DOI: $10.14707 / a j b r .190055$

\title{
Intention to Use Mobile Payment System by Ethnicity: A Partial Least Squares Multi-group Approach
}

\author{
Kim-Lim Tan \\ Entrepreneur Resource Centre (ERC) Institute, Singapore \\ Faculty of Business, Curtin University, Sarawak, Malaysia \\ Mumtaz Ali Memon \\ Air University School of Management, Air University, Islamabad, Pakistan \\ Pei-Lin Sim \\ Faculty of Hospitality \& Tourism Management, UCSI University, Sarawak, Malaysia \\ Choi-Meng Leong \\ Faculty of Business and Information Science, UCSI University, Sarawak, Malaysia \\ Fathan K. Soetrisno \\ School of Business Management, University College of Technology Sarawak, Malaysia \\ Kashif Hussain \\ Faculty of Hospitality \& Tourism Management, UCSI University, Kuala Lumpur, Malaysia
}

\begin{abstract}
With recent developments in communication technologies, mobile payment (Mpayment) systems have gained popularity as a method to facilitate payment transactions. Despite that, the intention of adopting M-payment in the developing market as well as the implication of ethnicity in the context of developing countries remains largely unanswered. Following the theory of planned behaviour, this study examines the effects of attitude, subjective norm and perceived behavioural control on intention towards the use of an M-payment system among Malays and Chinese in Malaysia. Beliefs are included as antecedent variables so as to enhance understanding of the subject matter. Data was collected from 311 respondents. The partial least squares structural equation modelling (PLS-SEM) was employed to assess the research model. The moderating effect of ethnicity was tested by using a multi-group approach (MGA) from two subsamples (i.e., Chinese and Malays). Results highlight the need to understand the determinants to users' intention towards M-payment systems in developing markets. It demonstrates the importance of knowing what is shared and what is not in multi-ethnic and multi-cultural countries like Malaysia. The results provide managerial implications into effective service operation and marketing of an M-payment system.
\end{abstract}

Keywords: Mobile Payment, Intention, Belief, Developing Market, Ethnicity, Partial Least Squares, Multi-group Approach

Publication Details: Received 7 Dec 2018; Revised 2 March 2019; Accepted 8 Apr 2019 


\section{Introduction}

The fourth industrial revolution presents opportunities and challenges for businesses and consumers alike. It has transformed how goods are being produced, how businesses communicate with one another and how individuals are obtaining knowledge, goods and services. In recent years, the payment schemes used in commerce activities have been transformed with the growth and innovation of technologies such as the internet, social networks, smartphones and mobile apps. It revolutionizes customers' shopping experience by leveraging on payment using mobile devices instead of physical wallet payment. In fact, M-payment is recognised as one of the emerging payment methods (Flatraaker, 2013) that permit consumers to transfer money and make payment conveniently via wireless networking technologies (WI-FI). In other words, M-payment "includes the completion of payments and transactions between two parties in a fast, convenient, safe, and simple way, anytime and anywhere, using a mobile device" (Liébana-Cabanillas et al., 2014, p. 464).

The widespread use of mobile devices and its perpetual proximity to the users has led to a profound change in our society. At the present time, the M-payment system is becoming a digital tool for payment now and the near future, not only in developed countries but also in developing markets such as Malaysia (Kim et al., 2010b). It is reported that over 20 million Malaysian consumers are internet users (The Star Online, 2015). Furthermore, approximately half of Malaysians own more than one mobile device and almost a quarter of them access the internet using their smartphones (The Star Online, 2014). In Malaysia, the rate of M-payment usage has seen tremendous growth in these few years. A recent mobile point-of-sale payments report revealed that the transaction value in Malaysia's mobile payment segment was up to US\$893 million in the year of 2019 and this is foreseen to show an annual growth rate of $30.1 \%$ to US \$1,968 million in the year of 2022 (Statista, 2019). Given the prevalent use of mobile devices and the internet, the M-payment system is proving to be a well-accepted paying method for individual consumers and a useful mechanism to expedite payment for government bodies and business organizations (Ondrus \& Pigneur, 2006).

Due to the widespread use of e-commerce, it has drawn much attention from researchers in investigating M-payment intention among consumers. Despite the growing interest, gaps still remain. Firstly, the study of M-payment systems in developing countries (i.e., Malaysia) is still found wanting. Hence, the present study attempts to determine the effect of antecedent variables on intention towards $M$ payment using the Theory of Planned Behaviour (TPB). TPB is the most appropriate theoretical basis for examining the adoption of M-payment since it has been widely used to predict and understand user perceptions of system use and the probability of adopting an online system in a wide range of behavioural disciplines (Lee, 2009).

Secondly, ethnicity is gaining recognition as a powerful predictor human attitude and plays a significant role in consumer behaviour (Mansori et al., 2015; Pires \& Stanton, 2000). Numerous scholars asserted that individuals' beliefs and norms stemmed from their personal ethnic and religious practices. For instance, ethnicity is predicted to significantly affect the level of participation in the use of new technology (Coverdale \& Morgan, 2013). Mohd Suki and Ramayah (2010) also posit that there is an extreme lack in the literature that articulates intention towards M-payment systems across 
ethnic groups in a multi-ethnic and culturally diverse country. Similarly, a survey conducted in Malaysia (Sulaiman et al., 2007) reveals that both demographic and psychographic variables affect the adoption of new innovations such as m-bankingin particular, age, gender, personal income, and education. Thus, this present study intends to assess the boundary condition between two most dominant ethnic groups in the country, namely Malays and Chinese, on the subject matter in order to narrow the gap in the use of the mobile payment system.

This study is comprised of (1) the introduction (2) literature review where we discuss M-payment and intention to use an M-payment system (3) development of seven hypotheses, (4) research methodology and the results obtained, and finally (5) managerial implications and limitations of the study.

\section{Literature Review}

\section{Theory of Planned Behavior}

Originating in the field of psychology, the phenomenon of technology acceptance has been studied widely by applying a range of alternative theories and models. The theory of planned behaviour (TPB) is an extension of the theory of reasoned action (TRA) which is used to explain consumer behaviour (Ajzen, 1991). TPB posits three conceptually independent determinants of intention, which are attitude, subjective norm and perceived behavioural control. These three determinants are in turn predicted by three distinctive beliefs respectively; namely, behavioural beliefs, normative beliefs and control beliefs. They serve as antecedent variables in this study. TPB is adopted as the underlying theory due to its validated variables and relevance in understanding human behaviour (Lizin et al., 2017; Ye et al., 2017; Al-Debei et al., 2013).

\section{Mobile Payment System}

E-payment is generally defined as payment processed and received electronically (Humphrey et al., 1996). Driven by the advantages of being flexible and convenient, e-payment allows individuals to complete transactions over the internet anywhere and at any time (Weir et al., 2006). M-payment, which is a particular form of e-payment, enables mobile users to make payments using internet-connected mobile devices (Dahlberg et al., 2008). An M-payment system takes advantage of wireless and communication technologies since it allows payment to be made via SMS message, WAP online billing, PIN number transmission, Mobile Web, direct-to-subscriber bill and direct to credit cards transactions through mobile phones (Kim et al., 2010a). It is shown that the ease of usage, the convenience it provides, and the timeliness in completing the payment transactions are key attributes in influencing the adoption of mobile technologies and services (Ting et al., 2016; The Star Online, 2014). 


\section{Intention to Use Mobile Payment System}

Past research has established that beliefs and attitudes are predictors of behavioural intention (Wang et al., 2009; Ajzen, 2011). The intention is often being used to understand how attitude can have an effect on actual behaviour (Huang et al., 2004), and how negative attitude would lead to unfavourable intention and behaviour (Stevenson et al., 2000). Empirical evidence shows that favourable intention among mobile users towards mobile technology is a corollary of their positive beliefs (Au \& Kauffman, 2008, Qin et al., 2018). It is asserted that the identifying of determinants of behavioural intention provides better forecasts than a simple extrapolation from past sales trends (Armstrong et al., 2000). A recent survey shows that as much as $70 \%$ of Malaysians are ready to embrace an M-payment system as part of their daily routines (Wong, 2017). Given its robust development, it is imperative to examine how belief shapes local mobile users' intention in their willingness to adopt an M-payment system. That is to say, the outcomes of this study potentially can offer insights complimenting policy makers and developers' efforts in shaping individuals' motivation and intention towards adopting M-payment services as part of their daily routines.

\section{Belief}

As stated earlier, TPB is an extended version of TRA that has been deployed across studies of different disciplines such as online gaming (Alzahrani et al., 2017), social media usage (Tariq et al., 2017), marketing (Hongwei \& Liuning, 2011), hospitality (Han et al., 2010) and employees' behaviour (Jimmieson et al., 2008). Within TPB, belief is the underlying psychological determinant that determines behaviour (Ajzen, 1991). In other words, in order to design interventions to alter intentions towards adoption of M-payment within the local community in Malaysia, one needs to be aware of "not only what are the salient beliefs regarding this behaviour in this population, but also which beliefs are associated with intentions and behaviour" (French \& Cooke, 2012, p. 2). Three salient beliefs are identified following past literature. First, behavioural belief comprises perceived usefulness, perceived ease of use, trust and perceived safety (Kim et al., 2010b). Second, interpersonal and external influence forms normative belief (Chibber, 2012). Lastly, control belief is made up of two factors: self-efficacy and facilitating condition (Carlsson et al., 2006; Jeong \& Yoon, 2013). From Figure 1, all belief factors serve as antecedents in the model, while attitude, subjective norm and perceived behavioural control are constructed as independent variables. Intention is the only dependent variable in the model. Accordingly, seven hypotheses are formulated to address research problems and objectives. 


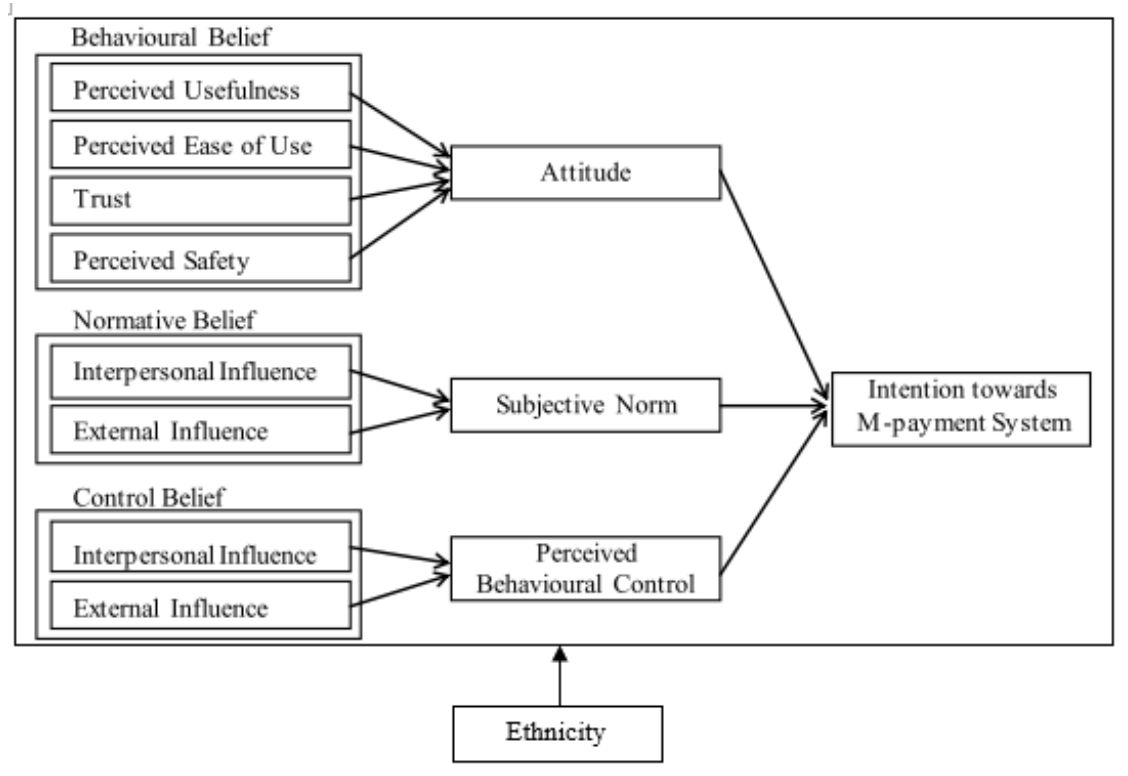

Figure 1: Conceptual Framework of the Study

\section{Hypotheses Development}

\section{Behavioural Belief and Attitude}

Behavioural belief comprises four dimensions: perceived usefulness, perceived ease of use, trust, and perceived safety. In the technology acceptance model (TAM), Davis et al. (1989) theorise that perceived ease of use and perceived usefulness are two fundamental beliefs that affect the user's attitude toward technology adoption. As explained by Davis (1989), perceived usefulness refers to the individual's perception that using a certain system is effortless or simply easy to do. This term is considered to be one of the qualities of the greatest impact on the acceptance of new technology. Also, Norazah Mohd and Norbayah Mohd (2011) confirmed that perceived ease of use has a double impact on attitude, due to its self-efficacy and instrumentality. Davis (1989) defined perceived ease of use as the degree to which a person believes that using a particular system would be free of effort.

In the present study, trust is consistently identified as a key predictor for using an Mpayment system. Users are frequently doubtful about the outcomes of mobile transactions (Siau et al., 2004), especially towards the potential risk from financial loss (Shin, 2010). Numerous scholars have included the significance of trust in the studies of consumer behaviour (Misra \& Wickamasinghe, 2004). Trust not only reduces fraud, fears, worries, and risks (Gefen et al., 2003) but also leads to a higher adoption rate. Shin (2010) found that trust positively influences the intention to adopt the use of M-payments. In fact, perceived ease of use and perceived usefulness are consistently found across literature, such as in Faqih (2013), to be the drivers of attitude that influence the adoption of online technology. Therefore, the following hypothesis is formulated: 
H1 Behavioural belief (perceived usefulness, perceived ease of use, trust and perceived safety) will have a positive effect on attitudes towards adopting an M-payment system.

\section{Normative Belief and Subjective Norm}

Normative belief includes two main constructs which are interpersonal influence and external influence. That is to say, it involves one's perception of the social pressures towards conformity of behaviour or the relevancy of other people's beliefs that exhibit influence on one's behaviour (Ajzen, 2011). Herein lays the perception of the importance of these influences over the individual. In other words, if the community and referents are significant to the individual such as the person's spouse, family and close friends, there is a higher motivation for one to perform the act. Simply, it is assumed that the normative beliefs, in combination with the person's motivation to comply with the behaviour, determine the subjective norm.

Subjective norm is a cohesive glue that by performing a similar behaviour, it (1) gives individuals with legitimacy to be part of the group, and (2) establishes their rank in the group as well (Minton et al., 2018). Evidence from varied sources support this argument demonstrating that the strength of ties one has with his or her immediate environment plays a key role in influencing the decision to partake in any given behaviour. For instance, Fang et al. (2017) showed that normative beliefs have a positive influence on social norms and attitudes, which in turn, drive one's behaviour towards pro-environmental practices.

Therefore, based on the discussion presented above, there are sufficient grounds on which to postulate that normative belief has a positive effect on one's subjective norm towards M-payment, making the following hypothesis necessary.

H2 Normative belief (interpersonal influence and external influence) will have a positive effect on subjective norm towards adopting an M-payment system.

\section{Control belief and Perceived Behavioral Control}

Traditionally, the research on motivation and action has largely focused on the role of motives and needs (Ajzen \& Fishbein, 1980). However, studies found that the prediction of behaviour based solely on motives failed to yield expected outcomes, especially when engagement of behaviour is a result of conscious reflection (Ye et al., 2017). That is to say, individuals assess the feasibility of executing behaviour by doing an analysis on the level of task difficulty as well as the desirability of the action. This refers to the key concept of control belief that encompasses both self-efficacy and facilitating conditions.

Originated from the work of Bandura (1977), self-efficacy refers to the confidence to generate the necessary cognitive resources, to develop motivation, and to draw up action plans with the objective of completing a task. Individuals gain self-efficacy in numerous ways, including personal mastery of tasks, vicarious experience, verbal persuasion and emotional arousal (Bandura, 1977). Another component within the construct of control belief is facilitating condition. From the multitude of explanations presented by scholars such as Venkatesh et al. (2003), we synthesize that facilitating 
condition is an individual's perception on the presence of external resources such as policies, frameworks and infrastructure that facilitate the adoption of new technologies or the performance of a particular activity.

Putting self-efficacy and facilitating condition together, empirical evidence converges to a similar point demonstrating the malleable characteristics of control belief. That is to say, control belief can be systematically developed by putting in place the appropriate interventions. Moreover, having a control belief brings about corollaries that go beyond executing a specific behaviour. For instance, Manavipour and Saeedian (2016) show that the presence of control belief brings about a positive appraisal of oneself such as having better self-judgment and demonstrating selfkindness. In the same vein, perceived behavioural control refers to individuals' view of their ability and volition in performing a behaviour (Ajzen, 1991), which resembles the construct of self-efficacy and facilitating conditions. Leveraging on TPB, one can assume that the perceived behavioural control is a function of the total control beliefs that are present and accessible to the individual at that point in time. The presence of self-efficacy and facilitating conditions plays a crucial role, in influencing one's perceived behavioural control, which is reflected in the following hypothesis.

H3 Control belief (self-efficacy and facilitating condition) will have a positive effect on perceived behavioural control towards adopting an M-payment system.

\section{Attitude and Intention}

From a multitude of literature such as Fishbein (1963), we surmised that attitude is defined as an individual opinion towards behaviour. In the theory of planned behaviour (TPB), attitude is an essential pre-requisite of the intention to develop a particular behaviour (Ajzen and Fishbein, 1980). In fact, studies in the information systems context are found to have adopted a similar theoretical foundation in predicting one's behavioural intention to adopt information technologies (Qin et al., 2018; Alzahrani et al., 2017). Furthermore, studies such as Al-Debei et al. (2013) have further elucidated that an individual's attitude displays a positive significant relationship with behavioural intention in adopting online technologies, leading to the following hypothesis:

H4 Attitude will have a positive effect on intention towards adopting an Mpayment system.

\section{Subjective Norm and Intention}

As already mentioned, subjective norm is concerned with social pressure from others who are considered important and can influence individuals to behave, or not behave in a certain manner (Minton et al., 2018). Other than influencing the performance of behaviour, subjective norm involves the adoption of other people's viewpoints towards the same subject matter (Ajzen, 1991). Collectively speaking, the subjective norm is, therefore, a function of (1) desirability of performing a behaviour others want, and (2) motivation to adopt other people's views (Rivis and Sheeran, 2003). The construct of intention is central within TPB. Intentions encapsulate the factors that 
drive individuals to perform that additional mile or to put in additional effort in order to perform that behaviour (Ajzen, 1991).

Putting both constructs of subjective norm and intention together, studies have produced inconsistent results. For instance, Ham et al. (2015), who studied on green food consumption, shows that subjective norm had a significant relationship with intention. Yet, Krueger et al. (2000) found that subjective norm did not have any correlation with entrepreneurial intention. While there could be a multitude of reasons attributed to the difference, Ham et al. (2015) aptly summarise that the inconsistency "stems from the fact that a part of the information that this variable contains is already present in the desirability of undertaking a particular behaviour variable." (p. 740). In this regard, Ajzen (1991) acknowledged that intentions are more easily influenced by personal factors such as attitudes. Collectively speaking, this study, therefore, responds to the call of Krueger et al. (2000) to further examine the interplay of these two constructs and to find out in subsequent hypotheses, if ethnicity, is a possible variable that caused the inconsistencies in results. The following hypothesis is formulated:

H5 Subjective norm will have a positive effect on intention towards adopting an M-payment system.

\section{Perceived Behavioral Control and Intention}

Perceived behavioural control has been described by Ajzen (1991) as having the belief that he or she has the capabilities of exhibiting certain behaviour. Cognitively, perceived behavioural control can also be described as confidence over the control of behaviour such that one has the volition to decide to perform or not to perform a specific behaviour. $\mathrm{PBC}$ is, therefore, an individual belief that influences one's behavioural intention and motivation to perform the target behaviour. In this context, it is about the adoption of M-payment as part of its spending habits. As highlighted earlier, an intention results in displaying on one's level of confidence in performing any given behaviour. As an illustration, if one has the confidence that he or she has the required knowledge in performing transactions over mobile devices, the chances of him or her in displaying the behaviour is higher as compared to someone who does not have the pre-requisite knowledge. Based on the aforesaid assertions, it is therefore hypothesized that

H6 Perceived behavioural control will have a positive effect on intention towards adopting an M-payment system.

\section{Moderating Effect of Ethnicity}

Ethnicity involves a common cultural heritage, a sense of belongingness that is passed from one generation to another (Renzetti \& Curran, 1998). According to Drinivasa et al. (2014), ethnic diversity makes it critical to develop marketing strategies to target a specific consumer group. Furthermore, ethnicity is highly influential in shaping an individual's values and norms which is demonstrated in past studies across different contexts such as in Hamlett et al. (2008). In the same vein, studies such as Pires and Stanton (2000) have also shown that ethnicity plays an instrumental role in shaping one's purchasing intention. Research shows that ethnicity affects the level of 
participation in new technology (Coverdale \& Morgan, 2013). It has also shown an inequity in terms of access to the technology and more recently the skills necessary to make use of the Internet (Coverdale \& Morgan, 2013). It is described as beliefs or standards shared by groups that have an impact on the behaviours of individuals (Usunier, 2005). Since ethnicity is a dominant embodiment of culture, it is evident that beliefs, attitudes and behavioural intentions of individuals hinge upon their ethnicity (Legoh'erel et al., 2009). Hence, cultural value priorities can be seen in the manner of living in each ethnic group, and they become guiding principles to advocate the manner of their lives (Schwartz, 1999). This provides the basis to look into how ethnicity affects mobile users' responses towards M-payment system.

H7a Ethnicity moderates the relationship between behavioural belief and attitude.

H7b Ethnicity moderates the relationship between normative belief and subjective norm.

H7c Ethnicity moderates the relationship between control belief and perceived behavioural control.

H7d Ethnicity moderates the relationship between attitude and intention towards adopting an M-payment system.

H7e Ethnicity moderates the relationship between subjective norm and intention towards adopting an M-payment system.

H7f Ethnicity moderates the relationship between perceived behavioural control and intention towards adopting an M-payment system.

\section{Methodology}

As one of the leading developing countries in Asia, Malaysia was selected as the research site. Mobile users were the target population. Non-probability sampling using a purposive sampling technique was used to sample Malay and Chinese people who owned mobile devices (Memon et al., 2017). A sample size of 300 respondents was predetermined to be appropriate based on the type of analysis, number of variables and adequacy of effect size (Hair et al., 2010). A quantitative approach via self-administered questionnaire was adopted. A pre-test was conducted to ensure the questionnaire was well designed. 450 copies of the questionnaire were distributed in December 2014, and 351 copies were collected after a month, resulting in a response rate of $70 \%$. After initial screening, 311 copies were retained for data entry and subsequent analysis.

Other than a demographic section, the questionnaire contained statements about the seven variables in the study, as shown in Figure 1. Each of the variables was measured with multiple items to ensure data reliability using a 7-point Likert scale. It was adopted due to its discriminative power among responses (Hair et al., 2010). In order to achieve our research objectives and analyse the measurements and structural model, we considered the structural equation model (SEM) with the PLS approach, specifically the SmartPLS version 3.0. PLS-SEM can be viewed as quite similar to 
multiple regression analysis to examine the possible relationships with less emphasis on the measurement model (Hair et al., 2017). In addition, to carry out multi-group analyses between the race of Malay and Chinese, PLS is considered to be more appropriate to explore the differences between the two distinct groups (Aw et al., 2018). The respondents of Malay and Chinese are split into two data sets (Malay = 126 samples and Chinese $=185$ ). To estimate the structural model, all criteria such as convergent validity, discriminant validity, and measurement invariance were checked as suggested by Hair et al. (2017) as well as Ramayah et al. (2018). Subsequently, the analysis of ethnicity's moderating effect was tested via a multi-group analysis with ethnicity (i.e., Malay and Chinese) as a categorical variable to split the sample.

\section{Results}

\section{Data Preparation}

Before we performed any analysis, we first assessed the common method variance (CMV) by using Harman's Single Factor technique (Podsakoff et al., 2003). The result shows that the largest variance explained by the first factor was $45.62 \%$ of the total variance. This indicates that no general factor emerged from the factor analysis, as result, common method bias is not a significant problem for the current study (Podsakoff et al., 2003). Added to that, this study will also look into the demographic statistics of the sample data. Table 1 presents the demographic profiles of the respondents. Other ethnic groups, besides Malays and Chinese, are excluded from this study. Though Table 1 shows that there are 66 respondents who have never used online payment before, they are included because the study focuses on their intention, instead of their actual behaviour.

Table 1: Respondents' Demographic Details

\begin{tabular}{|llcc|}
\hline Variable & & Count & Percentage \\
\hline Gender & Male & 119 & 38.3 \\
& Female & 192 & 61.7 \\
\hline Ethnicity & Malay & 126 & 40.5 \\
& Chinese & 185 & 59.5 \\
\hline Education Level & Primary level & 2 & 0.60 \\
& Secondary level & 37 & 11.9 \\
& Tertiary level & 247 & 82.9 \\
& Others/Not stated & 25 & 4.6 \\
\hline Online Payment & Never & 66 & 21.2 \\
Frequency & Rarely, only when necessary & 99 & 31.8 \\
& Once per month & 71 & 22.8 \\
& Once per week/fortnight & 36 & 1.6 \\
& Few times per week & 39 & 12.5 \\
\hline & Total & 311 & 100.0 \\
\hline
\end{tabular}




\section{Measurement Model}

Convergent Validity refers to the extent to which a specified set of indicators for a construct converge or share a high proportion of variance in common (Hair et al., 2010). Factor loadings of the items, composite reliability (CR), and average variance extracted (AVE) are used to assess the convergent validity of the data (Hair et al., 2017). To ensure the indicators' of the reliability, the main loading and cross-loading of items are checked. Items which recommended a value of 0.5 should be retained (Hair et al., 2017). The AVE criterion is defined as the grand mean value of the squared loadings of the indicators associated with the construct. An AVE value of at least 0.5 and higher indicates that a latent variable is able to explain more than half of the variance of its indicators on average and thus it is considered as sufficient (Hair et al., 2017). CR refers to a block that is considered as homogeneous and a measure of internal consistency (Hair et al., 2017). CR is more suitable for PLS-SEM as compared with Cronbach's alpha, which prioritizes indicators according to their reliability during model estimation (Hair et al., 2017). CR should be higher than 0.7 as suggested by Hair et al. (2017). Drawing from all these criteria, we retained all the loading items which exceeded the recommended value of 0.6 (Chin, 1998). On the other hand, all the CR values of constructs were found to be a minimum threshold of 0.7. Also, the AVE scores of all the constructs exceeded the cut-off value of 0.5 (refer to Table 2).

Table 2: PLS Factor Loadings, CR, and AVE of Full, Malay and Chinese Samples

\begin{tabular}{|c|c|c|c|c|c|c|c|c|c|c|}
\hline \multirow[b]{2}{*}{ Construct } & \multirow[b]{2}{*}{ Items } & \multicolumn{3}{|c|}{ Full Sample $(\mathrm{n}=311)$} & \multicolumn{3}{|c|}{ Malay $(n=126)$} & \multicolumn{3}{|c|}{ Chinese (n=185) } \\
\hline & & 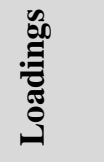 & $\sum_{4}^{5}$ & ชै & 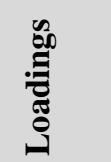 & $\sum_{4}^{5}$ & 己ै & 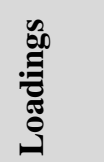 & $\sum_{4}^{n}$ & 气ี \\
\hline \multirow[t]{3}{*}{ Attitude } & ATT1 & 0.939 & 0.886 & 0.959 & 0.936 & 0.868 & 0.952 & 0.939 & 0.895 & 0.962 \\
\hline & ATT2 & 0.950 & & & 0.931 & & & 0.960 & & \\
\hline & ATT3 & 0.935 & & & 0.928 & & & 0.939 & & \\
\hline \multirow[t]{3}{*}{ Compatible } & COMP1 & 0.936 & 0.879 & 0.956 & 0.890 & 0.826 & 0.934 & 0.960 & 0.907 & 0.967 \\
\hline & COMP2 & 0.956 & & & 0.934 & & & 0.967 & & \\
\hline & COMP3 & 0.920 & & & 0.902 & & & 0.930 & & \\
\hline \multirow[t]{2}{*}{ Ease of Use } & EOU1 & 0.883 & 0.790 & 0.919 & 0.922 & 0.827 & 0.935 & 0.860 & 0.770 & 0.910 \\
\hline & $\begin{array}{l}\text { EOU2 } \\
\text { EOU3 }\end{array}$ & $\begin{array}{l}0.907 \\
0.876\end{array}$ & & & $\begin{array}{l}0.916 \\
0.889\end{array}$ & & & $\begin{array}{l}0.905 \\
0.868\end{array}$ & & \\
\hline \multirow{3}{*}{$\begin{array}{l}\text { External } \\
\text { Influence }\end{array}$} & EI1 & 0.832 & 0.734 & 0.892 & 0.819 & 0.661 & 0.854 & 0.833 & 0.754 & 0.902 \\
\hline & EI2 & 0.866 & & & 0.774 & & & 0.894 & & \\
\hline & EI3 & 0.871 & & & 0.844 & & & 0.878 & & \\
\hline \multirow{3}{*}{$\begin{array}{l}\text { Facilitating } \\
\text { Condition }\end{array}$} & FC1 & 0.881 & 0.803 & 0.925 & 0.901 & 0.804 & 0.925 & 0.873 & 0.804 & 0.925 \\
\hline & FC2 & 0.910 & & & 0.887 & & & 0.921 & & \\
\hline & FC3 & 0.898 & & & 0.902 & & & 0.895 & & \\
\hline \multirow[t]{3}{*}{ Intention } & INT1 & 0.957 & 0.913 & 0.969 & 0.945 & 0.898 & 0.964 & 0.963 & 0.919 & 0.972 \\
\hline & INT2 & 0.953 & & & 0.954 & & & 0.951 & & \\
\hline & INT3 & 0.957 & & & 0.944 & & & 0.962 & & \\
\hline
\end{tabular}




\begin{tabular}{lllllllllll}
\hline Perceived & PBC1 & 0.919 & 0.801 & 0.923 & 0.876 & 0.745 & 0.898 & 0.940 & 0.829 & 0.936 \\
Behavioural & PBC2 & 0.871 & & & 0.803 & & & 0.901 & & \\
Control & PBC3 & 0.894 & & & 0.907 & & & 0.889 & & \\
Interpersonal & II1 & 0.921 & 0.840 & 0.940 & 0.884 & 0.785 & 0.917 & 0.934 & 0.860 & 0.948 \\
Influence & II2 & 0.913 & & & 0.899 & & & 0.918 & & \\
& II3 & 0.916 & & & 0.876 & & & 0.929 & & \\
Self- & SE1 & 0.880 & 0.782 & 0.915 & 0.892 & 0.807 & 0.926 & 0.871 & 0.768 & 0.908 \\
Efficacy & SE2 & 0.927 & & & 0.929 & & & 0.926 & & \\
& SE3 & 0.844 & & & 0.873 & & & 0.829 & & \\
Subjective & SN1 & 0.879 & 0.842 & 0.941 & 0.839 & 0.809 & 0.927 & 0.883 & 0.844 & 0.942 \\
Norm & SN2 & 0.946 & & & 0.932 & & & 0.947 & & \\
& SN3 & 0.927 & & & 0.924 & & & 0.924 & & \\
Trust & TRUST1 & 0.835 & 0.836 & 0.938 & 0.777 & 0.794 & 0.920 & 0.866 & 0.861 & 0.949 \\
& TRUST2 & 0.957 & & & 0.949 & & & 0.963 & & \\
& TRUST3 & 0.945 & & & 0.937 & & & 0.952 & & \\
Perceived & USE1 & 0.925 & 0.861 & 0.961 & 0.950 & 0.882 & 0.968 & 0.908 & 0.849 & 0.957 \\
Usefulness & USE2 & 0.954 & & & 0.960 & & & 0.950 & & \\
& USE3 & 0.938 & & & 0.936 & & & 0.941 & & \\
& USE4 & 0.895 & & & 0.910 & & & 0.885 & & \\
\hline
\end{tabular}

Note: AVE (Average Variance Extracted); CR (Composite Reliability)

In terms of discriminant validity, it can be defined as a situation when two or more distinctively different concepts are not correlated to one another (Hair et al., 2017). According to Fornell and Larcker (1981) criterion, the squared root of AVE for each latent construct, should be higher than the correlations of any other latent construct. Based on Table 3, the discriminant validity was assessed for both the full and split sample (i.e., Malay and Chinese) by comparing the correlations between constructs and the square root of the average variance extracted for that construct, and they were found to be satisfactory (Fornell \& Larcker, 1981).

Table 3: Discriminant Validity

\begin{tabular}{lccccccc}
\hline Full Sample & $\mathbf{1}$ & $\mathbf{2}$ & $\mathbf{3}$ & $\mathbf{4}$ & $\mathbf{5}$ & $\mathbf{6}$ & $\mathbf{7}$ \\
\hline 1. Attitude & 0.941 & & & & & & \\
2. Behavioural Belief & 0.798 & Formative & & & & & \\
3. Control Belief & 0.779 & 0.759 & Formative & & & & \\
4. Intention & 0.785 & 0.791 & 0.724 & 0.956 & & & \\
5. Normative Belief & 0.552 & 0.593 & 0.499 & 0.576 & Formative & & \\
6. PBC & 0.738 & 0.754 & 0.824 & 0.764 & 0.506 & 0.895 & \\
7. Subjective Norm & 0.629 & 0.587 & 0.529 & 0.608 & 0.806 & 0.519 & 0.918 \\
\hline Malay Sample & $\mathbf{1}$ & $\mathbf{2}$ & $\mathbf{3}$ & $\mathbf{4}$ & $\mathbf{5}$ & $\mathbf{6}$ & $\mathbf{7}$ \\
\hline 1. Attitude & 0.932 & & & & & & \\
2. Behavioural Belief & 0.76 & Formative & & & & & \\
3. Control Belief & 0.782 & 0.796 & Formative & & & & \\
4. Intention & 0.724 & 0.785 & 0.735 & 0.948 & & & \\
5. Normative Belief & 0.563 & 0.654 & 0.611 & 0.519 & Formative & & \\
6. PBC & 0.712 & 0.767 & 0.773 & 0.787 & 0.604 & 0.863 & \\
7. Subjective Norm & 0.655 & 0.684 & 0.671 & 0.59 & 0.684 & 0.603 & 0.899 \\
\hline
\end{tabular}




\begin{tabular}{lccccccc}
\hline Chinese Malay & $\mathbf{1}$ & $\mathbf{2}$ & $\mathbf{3}$ & $\mathbf{4}$ & $\mathbf{5}$ & $\mathbf{6}$ & $\mathbf{7}$ \\
\hline 1. Attitude & 0.946 & & & & & & \\
2. Behavioural Belief & 0.818 & Formative & & & & & \\
3. Control Belief & 0.775 & 0.737 & Formative & & & & \\
4. Intention & 0.813 & 0.793 & 0.72 & 0.959 & & & \\
5. Normative Belief & 0.532 & 0.561 & 0.444 & 0.587 & Formative & & \\
6. PBC & 0.749 & 0.743 & 0.853 & 0.751 & 0.45 & 0.911 & \\
7. Subjective Norm & 0.61 & 0.537 & 0.463 & 0.606 & 0.84 & 0.472 & 0.918 \\
\hline
\end{tabular}

Note: PBC (Perceived Behavioural Control Diagonal elements are the square root of the AVE of the reflective scales while the diagonals are the correlations between construct.

To validate the formative measures, multicollinearity between indicators was also assessed (Cheah et al., 2018). Using PLS-SEM, a VIF value of 3.3 and higher indicates a potential collinearity problem (Diamantopoulos \& Siguaw, 2006). Based on Table 4, all sub-dimensions (i.e., compatible, ease of use, external influence, facilitating condition, interpersonal influence, perceived usefulness, self-efficacy and trust) have passed the criterion. Furthermore, the significance and relevance of the outer weights of the formative constructs were examined. Table 4 shows that all formative indicators were significant and also they were not deleted because prior research and theory provided support for the relevance of these sub-dimension constructs.

Table 4: Measurement Properties for Formative Construct

\begin{tabular}{lcccccc}
\hline \multirow{2}{*}{ Formative Construct } & \multicolumn{2}{c}{ Full Set Data $(\mathbf{n}=311)$} & \multicolumn{2}{c}{ Malay $(\mathbf{n = 1 2 6})$} & \multicolumn{2}{c}{ Chinese $(\mathbf{n = 1 8 5})$} \\
\cline { 2 - 7 } & VIF & t-value & VIF & t-value & VIF & t-value \\
\hline Compatible & 2.584 & $31.133 * *$ & 2.673 & $21.550 * *$ & 2.553 & $25.674 * *$ \\
Ease of Use & 2.419 & $21.658^{* *}$ & 2.279 & $15.708 * *$ & 2.674 & $15.831 * *$ \\
External Influence & 2.364 & $36.931 * *$ & 2.125 & $24.033 * *$ & 2.455 & $32.030^{* *}$ \\
Facilitating Condition & 1.898 & $40.405 * *$ & 1.567 & $23.383 * *$ & 2.222 & $31.639 * *$ \\
Interpersonal Influence & 2.364 & $36.397 * *$ & 2.125 & $24.038 * *$ & 2.455 & $29.688 * *$ \\
Perceived Usefulness & 2.700 & $33.612 * *$ & 2.544 & $25.727 * *$ & 2.940 & $25.359 * *$ \\
Self-Efficacy & 1.898 & $41.405 * *$ & 1.567 & $21.940 * *$ & 2.222 & $33.613 * *$ \\
Trust & 1.551 & $17.226 * *$ & 1.710 & $11.695 * *$ & 1.532 & $14.096 * *$ \\
\hline
\end{tabular}

Note: VIF (Variance Inflation Factor)

This study also used the standardized root mean square residual (SRMR) as a goodness of fit measure for PLS-SEM proposed by Henseler et al. (2014). The SRMR is defined as the difference between the observed correlation and the predicted correlation (Cheah et al., 2018). Thus, it allows assessing the average magnitude of the discrepancies between observed and expected correlations as an absolute measure of (model) fit criterion. The result of SRMR as a goodness-of-fit (GOF) measure for PLS-SEM has shown a good fit for all three data (Table 5), where the full data indicate the value of 0.078 , Chinese data pointed the score of 0.087 as well as Malay indicate the score of 0.090. Thus, all three data show a good fit of the model, measuring a value less than 0.10 and of 0.08 (Hu \& Bentler, 1999).

Table 5: SRMR Result of Assessing Model Fit

\begin{tabular}{lc}
\hline Data Set & SRMR Result for Composite Models \\
\hline Full Set $(\mathrm{n}=380)$ & 0.078 \\
Chinese $(\mathrm{n}=185)$ & 0.087 \\
Malays $(\mathrm{n}=126)$ & 0.090 \\
\hline
\end{tabular}


Next, the measurement invariance is tested. Hair et al. (2017) have mentioned that researchers should ensure the construct measures are invariant across the groups while comparing path coefficients across the groups. The invariance test is conducted to see whether item measurements differ across the two groups of races (Malay and Chinese). The criterion is at least two items should not differ in the measurement items of each construct. Table 6 shows that the there is no significant difference between the two groups.

\section{Result of Testing the Structural Model}

The structural model specifies the causal relationships among constructs in the model (path coefficients and the coefficient of determination: $\mathrm{R}^{2}$ value). Together, the $\mathrm{R}^{2}$ and the path coefficients (beta and significance) show how well the data supported the hypothesized model (Chin, 1998). We used the bootstrapping method with a resampling of 1000 to estimate the significance of the path coefficient (Chin, 1998). The path coefficients for full and split data are shown in Table 7 and Table 8 .

From the analysis, the study found that behaviour belief on attitude was significant for the full data $(\beta=0.798, t$-value $=30.890 * *)$, Malay data $(\beta=0.760, t$-value $=12.581 * *)$ and Chinese data $\left(\beta=0.818, t\right.$-value $\left.=32.488^{* *}\right)$. Based on these findings, the $\mathrm{R}^{2}$ value for all three groups of data indicates that more than $50 \%$ of the variance in attitude can be explained by behavioural belief. Besides that, $\mathrm{H} 2$ was also supported in the full data $\left(\beta=0.806, t\right.$-value $\left.=29.991^{* *}\right)$, Malay data $\left(\beta=0.684, t\right.$-value $\left.=9.417^{* *}\right)$, and Chinese data $\left(\beta=0.840, t\right.$-value $\left.=32.010^{* *}\right)$. Hence, the findings show that the full data and Chinese data have more than $50 \%$ of the variance in the subjective norm that can be explained by normative belief. However, for the Malay data, about $46.8 \%$ of the variance in the subjective norm can be explained by normative belief. Similarly for $\mathrm{H} 3$, the results were supported in the full data set $\left(\beta=0.824, t\right.$-value $\left.=33.810^{* *}\right)$, Malay data $\left(\beta=0.773, t\right.$-value $\left.=18.708^{* *}\right)$, and Chinese data $\left(\beta=0.853, t\right.$-value $\left.=29.914^{* *}\right)$. In terms of the $\mathrm{R}^{2}$, the results indicate that the $\mathrm{R}^{2}$ value for all three data sets show that more than $50 \%$ of the variance in perceived behavioural control can be explained by control belief.

Furthermore, the results also showed that both attitude and perceived behavioural control have significant results for the Full, Malay and Chinese data sets. In detail, the results of $\mathrm{H} 4$ were supported in the full data set $(\beta=0.401, t$-value $=4.797 * *)$, Malay data $\left(\beta=0.297, t\right.$-value $\left.=2.033^{*}\right)$, and $\left(\beta=0.474, t\right.$-value $\left.=5.981^{* *}\right)$. As for H6, the results were supported in the full data set $\left(\beta=0.388, t\right.$-value $\left.=4.707^{* *}\right)$, Malay data $(\beta=0.530, t$-value $=3.579 * *)$, and Chinese data $(\beta=0.316, t$-value $=3.887 * *)$. In terms of $\mathrm{H} 5$ (subjective norm on intention), the results only indicate that the full data $\left(\beta=0.155, t\right.$-value $\left.=2.712^{* *}\right)$ and Chinese data $\left(\beta=0.168, t\right.$-value $\left.=2.743^{* *}\right)$ were significant; which the Malay data $(\beta=0.076, t$-value $=0.788)$ was not. Drawing from these findings of $\mathrm{H} 4$ to $\mathrm{H} 6$, the $\mathrm{R}^{2}$ results indicate that the highest variance in intention which can be explained by attitude, subjective norms and perceived behavioural control was from Chinese data $(72.5 \%)$, and then followed by the full sample (70.5\%) and lastly the Malay Data (67.7\%). 
Table 6: Measurement Invariance Test

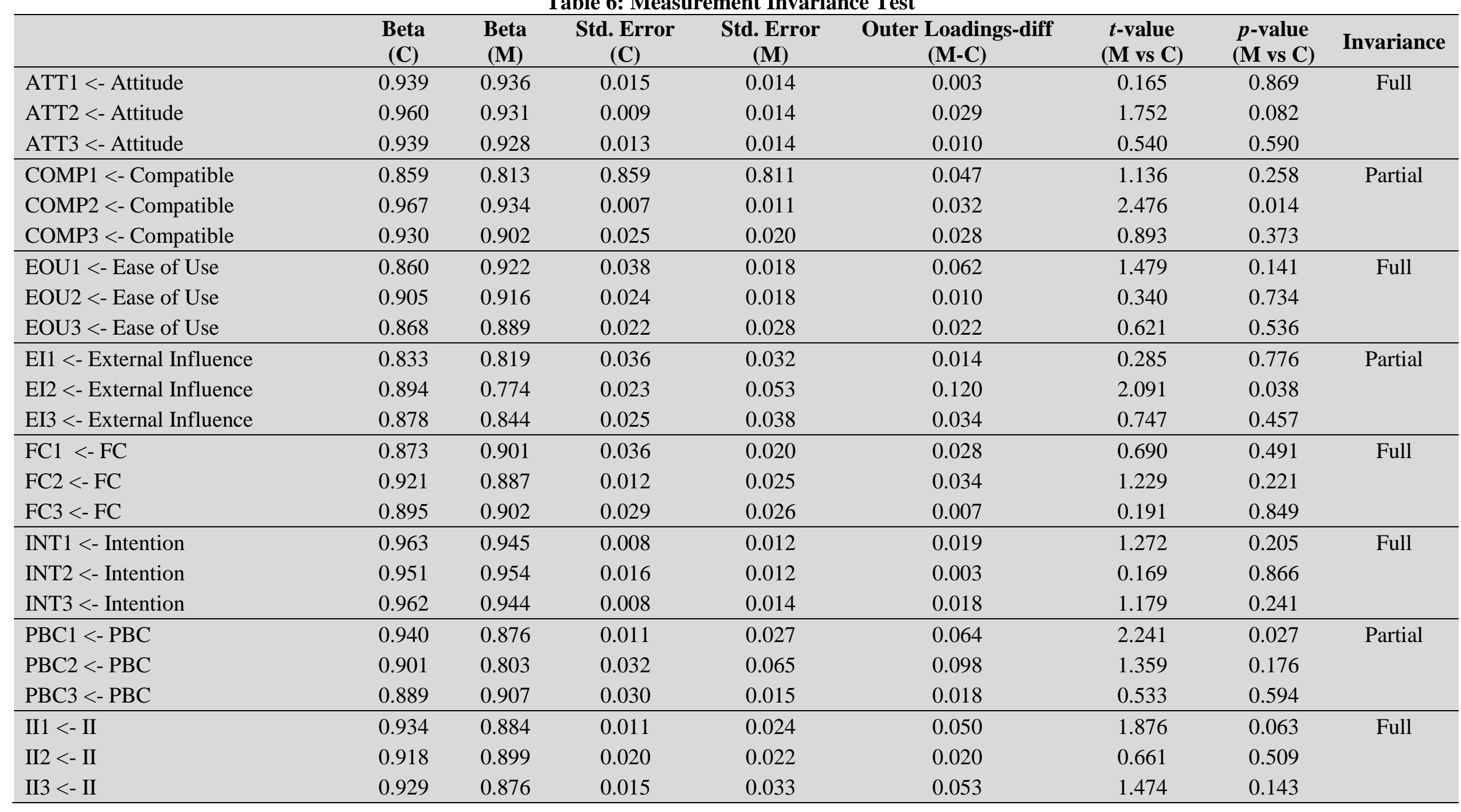




\begin{tabular}{|c|c|c|c|c|c|c|c|c|}
\hline SE1 <- Self-Efficacy & 0.871 & 0.892 & 0.034 & 0.020 & 0.021 & 0.542 & 0.589 & Full \\
\hline SE2 <- Self-Efficacy & 0.926 & 0.929 & 0.011 & 0.012 & 0.004 & 0.218 & 0.828 & \\
\hline SN1 <- Subjective Norm & 0.883 & 0.839 & 0.026 & 0.045 & 0.044 & 0.837 & 0.404 & Full \\
\hline SN3 <- Subjective Norm & 0.924 & 0.924 & 0.020 & 0.014 & 0.000 & 0.008 & 0.994 & \\
\hline TRUST1 <- Trust & 0.866 & 0.777 & 0.029 & 0.075 & 0.090 & 1.126 & 0.262 & Full \\
\hline TRUST2 <- Trust & 0.963 & 0.949 & 0.006 & 0.010 & 0.014 & 1.164 & 0.246 & \\
\hline USE2 <- PU & 0.950 & 0.960 & 0.009 & 0.008 & 0.010 & 0.810 & 0.419 & \\
\hline USE3 <- PU & 0.941 & 0.936 & 0.011 & 0.014 & 0.005 & 0.275 & 0.784 & \\
\hline USE4 <- PU & 0.885 & 0.910 & 0.034 & 0.019 & 0.025 & 0.640 & 0.523 & \\
\hline
\end{tabular}

Note: C (Chinese), M (Malays); FC (Facilitating Condition), PBC (Perceived Behavioral Control); II (Interpersonal Influence)

Table 7: Result for Direct Relationship

\begin{tabular}{|c|c|c|c|c|c|c|c|c|c|c|c|c|c|}
\hline \multirow{2}{*}{\multicolumn{2}{|c|}{ Hypothesis }} & \multicolumn{4}{|c|}{ Full Sample $(n=311)$} & \multicolumn{4}{|c|}{ Malay $(n=126)$} & \multicolumn{4}{|c|}{ Chinese $(n=185)$} \\
\hline & & $\begin{array}{l}\text { Std. } \\
\text { Beta }\end{array}$ & $\begin{array}{c}\text { Std. } \\
\text { Error }\end{array}$ & $\begin{array}{c}t- \\
\text { value }\end{array}$ & Result & $\begin{array}{l}\text { Std. } \\
\text { Beta }\end{array}$ & $\begin{array}{c}\text { Std. } \\
\text { Error }\end{array}$ & $\begin{array}{c}t- \\
\text { value }\end{array}$ & Result & $\begin{array}{l}\text { Std. } \\
\text { Beta }\end{array}$ & $\begin{array}{c}\text { Std. } \\
\text { Error }\end{array}$ & $\begin{array}{c}t- \\
\text { value }\end{array}$ & Result \\
\hline H1 & BB -> Attitude & 0.798 & 0.026 & $30.890 * *$ & $\mathrm{~S}$ & 0.760 & 0.060 & $12.581 * *$ & $\mathrm{~S}$ & 0.818 & 0.025 & $32.448 * *$ & $\mathrm{~S}$ \\
\hline $\mathrm{H} 2$ & $\mathrm{NB} \rightarrow \mathrm{SN}$ & 0.806 & 0.027 & $29.991 * *$ & S & 0.684 & 0.073 & $9.417 * *$ & S & 0.840 & 0.026 & $32.01 * *$ & S \\
\hline $\mathrm{H} 3$ & $\mathrm{CB}->\mathrm{PBC}$ & 0.824 & 0.024 & $33.810 * *$ & S & 0.773 & 0.041 & $18.708 * *$ & S & 0.853 & 0.029 & $29.914 * *$ & S \\
\hline $\mathrm{H} 4$ & Attitude $->$ Intention & 0.401 & 0.084 & $4.797 * *$ & S & 0.297 & 0.146 & $2.033 *$ & S & 0.474 & 0.079 & $5.981 * *$ & S \\
\hline $\mathrm{H} 5$ & SN -> Intention & 0.155 & 0.057 & $2.712 * *$ & S & 0.076 & 0.097 & 0.788 & NS & 0.168 & 0.061 & $2.743 * *$ & S \\
\hline H6 & PBC -> Intention & 0.388 & 0.082 & $4.707 * *$ & S & 0.530 & 0.148 & $3.579 * *$ & S & 0.316 & 0.081 & $3.887 * *$ & S \\
\hline
\end{tabular}

Note: $* * \mathrm{p}<0.01,{ }^{*} \mathrm{p}<0.05 ; \mathrm{BB}$ (Behavioural Belief), NB (Normative Belief), CB (Control Belief), PBC (Perceived Behavioural Control), SN (Subjective Norm); S (Supported), NS (Not Supported) 
Apart from that, this study also assessed the predictive relevance $\left(\mathrm{Q}^{2}\right.$ value $)$ of the path model. In this case, Stone and Geisser's $Q^{2}$ (Geisser, 1974) is often used to assess predictive relevance and can be calculated using the blindfolding procedure. Blindfolding procedure is a resampling technique that systematically deletes and predicts every data point of the indicators in the reflecting measurement model of the endogenous construct. This procedure is used to compare the original values with the predicted values. If the prediction is close to original values (i.e. there is a small prediction error), the path model has high predictive accuracy. Specifically, the estimation can be done by checking if the result of the $\mathrm{Q}^{2}$ value $>0$, indicating that the model has predictive relevance (Fornell \& Cha, 1994). Importantly, this $Q^{2}$ value can be calculated using cross-validated redundancy (CVR) (Hair et al., 2017). CVR is known as an indirect prediction of the omitted data points of indicators of the endogenous latent variables by the constructs that are predictors of the latent variable. Based on Table 8 , the results show that every $\mathrm{Q}^{2}$ value for attitude, subjective norm, perceived behavioural control and intention has the $\mathrm{Q}^{2}$ value of $>0$, which indicates predictive relevance and validity of the model.

Furthermore, this study also evaluates the effect size of the predictor constructs using Cohen's $\mathrm{f}^{2}$ (Cohen, 1988). The effect size $\left(\mathrm{f}^{2}\right)$ is a measurement used to assess the relative impact of a predictor construct on an endogenous construct (Cohen, 1988). Specifically, it analyzed how much a predictor construct contributes to the $\mathrm{R}^{2}$ value of target constructs in the structural model. According to (Cohen, 1988), $\mathrm{f}^{2}$ values of $0.35,0.15$, and 0.02 are considered large, medium, and small effect sizes, respectively. If an exogenous construct strongly contributes to explaining an endogenous construct the difference between R2 included and R2 excluded will be high, leading to a high $\mathrm{f}^{2}$. The effect size can be calculated using the formula below:

$$
f 2=\frac{R^{2} \text { included }-R^{2} \text { excluded }}{1-R^{2} \text { included }}
$$

Based on Table 8, the $\mathrm{f}^{2}$ score for the full data has shown a moderate effect size for both attitude ( $\left.f^{2}: 0.203\right)$ and perceived behavioural control $\left(f^{2}: 0.229\right)$, but a small effect size for subjective norm $\left(f^{2}=0.049\right)$. As for the Malay data, the $\mathrm{f}^{2}$ score for subjective norm has shown a medium effect size (0.224) and attitude indicates a small effect size (0.039). In terms of the Chinese data, the $\mathrm{f}^{2}$ score turns out to be vice-versa, where attitude has shown a medium effect size (0.289) and subjective norm indicates a small effect size (0.064).

Table 8: Result of $\mathbf{R}^{2}, Q^{2}$ and $\mathbf{f}^{2}$

\begin{tabular}{lllllllllll}
\hline \multirow{2}{*}{ Construct } & \multicolumn{3}{l}{ Full Sample $(\mathbf{n}=\mathbf{3 1 1})$} & \multicolumn{3}{c}{ Malay $(\mathbf{n}=\mathbf{2 1 5})$} & \multicolumn{4}{c}{ Chinese $(\mathbf{n}=165)$} \\
\cline { 2 - 12 } & $\mathbf{R}^{\mathbf{2}}$ & $\mathbf{Q}^{\mathbf{2}}$ & $\mathbf{f}^{\mathbf{2}}$ & $\mathbf{R}^{\mathbf{2}}$ & $\mathbf{Q}^{\mathbf{2}}$ & $\mathbf{f}^{\mathbf{2}}$ & $\mathbf{R}^{\mathbf{2}}$ & $\mathbf{Q}^{\mathbf{2}}$ & $\mathbf{f}^{\mathbf{2}}$ \\
\hline Behavioural Belief & - & - & - & - & - & - & - & - & - \\
Normative Belief & - & - & - & - & - & - & - & - & - \\
Control Belief & - & - & - & - & - & - & - & - & - \\
Attitude & 0.637 & 0.561 & 0.203 & 0.577 & 0.498 & 0.039 & 0.669 & 0.592 & 0.289 \\
Subjective Norm & 0.650 & 0.545 & 0.049 & 0.468 & 0.371 & 0.224 & 0.706 & 0.589 & 0.064 \\
PBC & 0.679 & 0.539 & 0.229 & 0.598 & 0.437 & 0.399 & 0.727 & 0.598 & 0.159 \\
Intention & 0.705 & 0.639 & - & 0.677 & 0.598 & - & 0.725 & 0.655 & - \\
\hline
\end{tabular}

Note: PBC (Perceived Behavioural Control) 
To explore the differences, we carried out a PLS multi-group analysis for the Malay and Chinese subsamples. We tested differences between the path coefficients across the respective two data sets and the results are shown in Table 9. Only two paths differ significantly between the two data sets namely, control belief and perceived behavioural control (t-value: 1.657*) and normative belief and subjective norm ( $\mathrm{t}=$ value: $\left.2.066^{* *}\right)$.

Table 9: Path Differences by Race (Malay and Chinese)

\begin{tabular}{lllllllll}
\hline & $\begin{array}{l}\text { Std } \\
\text { Beta } \\
(\mathbf{C})\end{array}$ & $\begin{array}{l}\text { Std } \\
\text { Beta } \\
(\mathbf{M})\end{array}$ & $\begin{array}{l}\text { Std. } \\
\text { Error } \\
(\mathbf{C})\end{array}$ & $\begin{array}{l}\text { Std. } \\
\text { Error } \\
(\mathbf{M})\end{array}$ & $\begin{array}{l}\text { Path } \\
\text { Coefficien } \\
\text { ts-diff } \\
(\mathbf{M}-\mathrm{C})\end{array}$ & $\begin{array}{l}\boldsymbol{t} \text {-Value } \\
\text { (M vs C) }\end{array}$ & Result \\
\hline ATT -> Intention & 0.474 & 0.297 & 0.082 & 0.152 & 0.177 & 1.033 & NS \\
BB -> Attitude & 0.818 & 0.760 & 0.027 & 0.062 & 0.058 & 0.867 & NS \\
CB -> PBC & 0.853 & 0.773 & 0.029 & 0.040 & 0.080 & $1.657^{*}$ & S \\
NB -> SN & 0.840 & 0.684 & 0.027 & 0.071 & 0.156 & $2.066^{* *}$ & S \\
PBC -> Intention & 0.316 & 0.530 & 0.083 & 0.150 & 0.214 & 1.253 & NS \\
SN -> Intention & 0.168 & 0.076 & 0.062 & 0.100 & 0.092 & 0.783 & NS \\
\hline
\end{tabular}

Note: BB (Behavioural Belief), CB (Control Belief), NB (Normative Belief), PBC (Perceived Behavioural Control), SN (Subjective Norm); M (Malay), C (Chinese)

\section{Findings and Discussions}

The results suggest that Chinese and Malay people are motivated differently towards the adoption of M-payment systems. When these results in Table 9 are combined with the pairwise path coefficients in Table 7, interesting findings can be observed.

It is clear that peer and community influence have little effect within the Malay community to adopt M-payment. This is reflected in the non-supported hypothesis in Table 7. To the Malay community, the ability and confidence in using the application is a more critical factor in influencing their intention. This is reflected in perceived behavioural control being the strongest predictor to intention.

At the same time, the findings suggest that Chinese consumers are more willing to adopt M-payment if they hold positive attitudes towards it. This is seen from attitude being the strongest predictor to intention. Following the result in hypothesis 1 , it also shows that behavioural belief that comprises four dimensions of perceived usefulness, perceived ease of use, trust and perceived safety, displayed medium effect on behavioural belief. This shows that other than the usability, security features that ensure transactions are done in a secured environment plays a role in influencing their intention to adopt M-payment as well (Ting et al., 2016). Like the Malay community, the results show that the functionality and user-friendliness of the M-payment system is a necessity in sustaining their intention to use it. It also confirms the impact of subjective norm on Chinese consumers, where they are more likely to embrace it if their peers or the community they belong to consider it to be acceptable.

When we compare the path differences, Table 9 shows that two paths display significant differences between the two data sets. They are (1) control belief $\rightarrow$ perceived behavioural control and (2) normative belief $\rightarrow>$ subjective norm. From the results, it reveals that the Chinese consumers place more emphasize on control belief than the Malay consumers. As explained earlier, control belief involves both components of self-mastery and the presence of facilitating conditions. This reinforces our earlier discussions that Chinese consumers not only are influence by 
the usability, but also the presence of conditions that encourage the performance of behaviour. Such conditions can be peer influenced and acceptance or approval from the community. At the same time, the results also show that Chinese consumers' place more emphasize on normative belief, which was explained earlier as the perception on the behavioural expectations from the community that he or she is part of. In other words, the adoption of M-payment will be shaped by the influences exerted on him or her by people he or she is in proximity with that he or she considers as important. In summary, the results demonstrate the long-term orientation culture of the Chinese community where they would fulfil social obligations just to be part of the community (Ekiz and $\mathrm{Au}, 2011$ ). Collectively speaking, these findings confirmed the chain reaction of TPB, which is consistent with previous research across different contexts (French and Cooke, 2012, Hongwei and Liuning, 2011, Han et al., 2010)

\section{Managerial Implications}

This study fulfils the objectives by showing not only the effect of the various determinants on intention towards adopting an M-payment system but also providing insights into the difference in responses between two ethnic groups. Notwithstanding that the Malaysian mobile users are beginning to accept M-payment systems, there are distinct differences between the Malay and Chinese people. Having a comprehensive view of the effectiveness of different determinants on intention across the two ethnic groups will ensure effective service operation and marketing campaigns.

With perceived behavioural control being a key determinant in shaping intention for both ethnicities, the government can conduct focus group discussions with end-users to solicit views and support, thereby, fostering one's positive appraisal and attitude towards the use of M-payments. At the same time, businesses can focus on designing a user-friendly M-payment tool such that it enhances one's self-efficacy and confidence in using it. At the same time, trials can be performed with users from different demographic profiles and different levels of IT literacy, which again is targeting at one's perceived behavioural control.

Concomitantly, public education initiatives and training can be organized to educate the public on the usefulness and operations of M-payments. Other than holding roadshows at populous areas where workers congregate, it should also be at rural and residential areas where the IT penetration rate has thus far been low. These will enhance one's sense of behavioural beliefs which are essential in shaping attitude towards the adoption of M-payment.

Lastly, to leverage on the findings relating on subjective norm, especially the in Chinese community, targeted marketing strategies can be developed where influential individuals, such as social media influencers and respected leaders of respective communities can be the spokespersons of M-payment. That is to say, this strategy can form part of the marketing communication plan and public education initiatives since interpersonal and external influence are key to influence M-payment behaviour. Views from these individuals will lend credence to the adoption of the software and will provide additional social pressures to encourage individuals to adopt M-payment in their daily activities. 


\section{Limitations and Conclusions}

Although this study has yielded important findings, there are limitations which future researchers can improve on. Firstly, the sample focuses on a particular developing country. It is important to note that one's attitude towards the adoption of advances in technology, such as M-payment, differs from country to country, especially those with advanced economies where IT penetration rate is high and adopting new technology is part of its culture (Dwivedi et al., 2016). Hence, our study awaits further replication of samples from countries across different cultures or even to do a cross-country comparison. In the same vein, future studies can also look into M-payment behaviour between generations so as to provide a more in-depth understanding about the subject matter and its potential heterogeneity (Ting et al., 2018). Lastly, the collection of data on the investigation of the relationship is cross-sectional, hence precluding causality. Future researchers can consider adopting a longitudinal design or to have a multisource data collection.

We will conclude this study by arguing that with the growing influence of Industry 4.0, the digitisation of processes is inevitable. Rather than designing and implementing the process unilaterally, it is crucial for policymakers to work with the different communities. This will ensure greater support, and in turn, facilitating the integration of technology in an individual's day-to-day activities.

\section{References}

Ajzen, I., (1991), The theory of planned behavior, Orgnizational Behavior and Human Decision Processes, vol. 50, pp. 179-211.

Ajzen, I., (2011), The theory of planned behaviour: Reactions and reflections, Psychology \& Health, vol. 26, no. 9, pp. 1113-27.

Ajzen, I., \& Fishbein, M., (1980), A theory of reasoned action, Prentice Hall.

Al-Debei, M. M., Al-Lozi, E., \& Papazafeiropoulou, A., (2013), Why people keep coming back to Facebook: Explaining and predicting continuance participation from an extended theory of planned behaviour perspective, Decision Support Systems, vol. 55, no. 1.

Alzahrani, A. I., Mahmud, I., Ramayah, T., Alfarraj, O., \& Alalwan, N., (2017), Extending the theory of planned behavior (TPB) to explain online game playing among Malaysian undergraduate students, Telematics and Informatics, vol. 34, no. 4, pp. $239-51$.

Armstrong, J. S., Morwitz, V. G., \& Kumar, V., (2000), Sales forecasts for existing consumer products and services: Do purchase intentions contribute to accuracy?, International Journal of Forecasting, vol. 16, no. 3, pp. 383-97.

Au, Y. A., \& Kauffman, R. J., (2008), The economics of mobile payments: Understanding stakeholder issues for an emerging financial technology application, Electronic Commerce Research and Applications, vol. 7, no. 2, pp. 141-64.

Aw, E. C. X., Cheah, J. H., Ng, S. I., \& Sambasivan, M., (2018), Breaking compulsive buying-financial trouble chain of young Malaysian consumers, Young Consumers, vol. 19, no. 3, pp. 328-44.

Bandura, A., (1977), Self-efficacy: Toward a unifying theory of behavioral change, Psychology Review, vol. 84, no. 2, pp. 191-215.

Carlsson, C., Walden, P., \& Bouwman, H., (2006), Adoption of 3G+ services in Finland, International Journal of Mobile Communications, vol. 4, no. 4. 
Cheah, J. H., Sarstedt, M., Ringle, C. M., Ramayah, T., \& Ting, H., (2018), Convergent validity assessment of formatively measured constructs in PLS-SEM, International Journal of Contemporary Hospitality Management, vol. 30, no. 11, pp. 3192-210.

Cheah, J. H., Memon, M. A., Chuah, F., Ting, H., \& Ramayah, T., (2018), Assessing reflective models in marketing research: A comparison between pls and plsc estimates, International Journal of Business and Society, vol. 19, no. 1, pp. 139-60.

Chibber, A., (2012), "Malaysian government to test mobile-payment acceptance", Retrieved from http://www.paymentssource.com/news/

Chin, W. W., (1998), Commentary: Issues and opinion on structural equation modeling, MIS Quarterly, vol. 22, no. 1, pp. 1-1.

Cohen, J., (1988), Statistical power analysis for the behavioral siences, Lawrence Erlbaum Associates.

Coverdale, T. S., \& Morgan, A. J., (2013), The influence of identity characteristics on eshopping enjoyment and e-loyalty among women online shoppers, Journal of Technology Research, vol. 4, pp. 1-19.

Dahlberg, T., Mallat, N., Ondrus, J., \& Zmijewska, A., (2008), Past, present and future of mobile payments research: A literature review, Electronic Commerce Research and Applications, vol. 7, no. 2, pp. 165-81.

Davis, F. D., (1989), Perceived usefulness, perceived ease of use, and user acceptance of information technology, MIS Quarterly, vol. 13, no. 3, pp. 319-40.

Davis, F. D., Richard, P. B., \& Paul, R. W., (1989), User acceptance of computer technology: A comparison of two theoretical models, Management Science, vol. 35, no. 8, pp. 982-1003.

Diamantopoulos, A., \& Siguaw, J. A. (2006), Formative versus reflective indicators in organizational measure development: A comparison and empirical illustration, British Journal of Management, vol. 17, no. 4, pp. 263-82.

Drinivasa, R., Srivastava, R. K., \& Bhanot, S., (2014), Influence of ethnicity on uniqueness \& snob value in purchase behaviour of luxury brands, Journal of Research in Marketing, vol. 2, no. 3, pp. 172-86.

Dwivedi, Y. K., Shareef, M. A., Simintiras, A. C., Lal, B., \& Weerakkody, V., (2016), "A generalised adoption model for services: A cross-country comparison of mobile health (m-health), Government Information Quarterly, vol. 33, no. 1, pp. 174-87.

Ekiz, E. H., \& Au, N., (2011), Comparing Chinese and American attitudes towards complaining, International Journal of Contemporary Hospitality Management, vol. 23, no. 3, pp. 327-43.

Fang, W.-T., Ng, E., Wang, C.-M., \& Hsu, M.-L., (2017), Normative beliefs, attitudes, and social norms: People reduce waste as an index of social relationships when spending leisure time, Sustainability, vol. 9, no. 10.

Faqih, K., (2013), Exploring the influence of perceived risk and internet self-efficacy on consumer online shopping intentions: Perspective of technology acceptance model, International Management Review, vol. 9, no. 1, pp. 67-77.

Fishbein, M., (1963), An investigation of the relationships between beliefs about an object and the attitude toward that object, Human Relations, vol. 16, no. 3, pp. 233-39.

Flatraaker, D.-I., (2013), Mobile payments changing the landscape of retail banking: Hype or reality, Journal of Payments Strategy \& Systems, vol. 7, no. 2, pp. 150-58.

Fornell, C., \& Larcker, D. F., (1981), Evaluating structural equation models with unobservable variables and measurement error, Journal of Marketing Research, vol. 18 , no. 1 , pp. 39-10.

French, D., \& Cooke, R., (2012), Using the theory of planned behaviour to understand binge drinking: The importance of beliefs for developing interventions, British Journal of Health Psychology, vol. 17, no. 1, pp. 1-17.

Gefen, D., Karahanna, E., \& Straub, D., (2003), Trust and TAM in online shopping: An integrated model, $M I S Q$., vol. 27, no. 1, pp. 51-90.

Geisser, S., (1974), A predictive approach to the random effect model, Biometrika, vol. 61, no. 1, pp. 101-07. 
Hair, J. F., Black, W. C., Babin, B. J., \& Anderson, R. E., (2010), Multivariate Data Analysis, Prentice Hall.

Hair, J. F., Hult, G. T. M., Ringle, C. M., \& Sarstedt, M., (2017), A primer on partial least squares structural equation modeling (PLS-SEM), 2nd ed., Sage Publications Ltd.

Ham, M., Jeger, M., \& Frajman Ivković, A., (2015), The role of subjective norms in forming the intention to purchase green food, Economic Research-Ekonomska Istraživanja, vol. 28, no. 1, pp. 738-48.

Hamlett, J., Bailey, A. R., Alexander, A., \& Shaw, G., (2008), Ethnicity and consumption: South asian food shopping patterns in Britain, 1947-75 1, Journal of Consumer Culture, vol. 8, no. 1, pp. 91-116.

Han, H., Hsu, L. T., \& Sheu, C., (2010), Application of the theory of planned behavior to green hotel choice: Testing the effect of environmental friendly activities, Tourism Management, vol. 31, no. 3, pp. 325-34.

Hongwei, Y., \& Liuning, Z., (2011), Extending TPB and TAM to mobile viral marketing: An exploratory study on American young consumers' mobile viral marketing attitude, intent and behavior, Journal of Targeting, Measurement and Analysis for Marketing, vol. 19, no. 2, pp. 85-98.

Hu, L. T., \& Bentler, P. M., (1999), Cutoff criteria for fit indexes in covariance structure analysis: Conventional criteria versus new alternatives, Structural Equation Modeling: A Multidisciplinary Journal, vol. 6, no. 1, pp. 1-55.

Huang, J.-H., Lee, B. C. Y., \& Ho, S. H., (2004), Consumer attitude toward gray market goods, International Marketing Review, vol. 21, no. 6, pp. 598-614.

Humphrey, D. B., Pulley, L. B., \& Vesala, J. M., (1996), Cash, paper, and electronic payments: A cross-country analysis, Journal of Money, Credit and Banking, vol. 28, no. 4, pp. 914-39.

Jeong, B. K., \& Yoon, T. E., (2013), An empirical investigation on consumer acceptance of mobile banking services, Business and Management Research, vol. 2, no. 1, pp. 3140.

Jimmieson, N. L., Peach, M., \& White, K. M., (2008), Utilizing the theory of planned behavior to inform change management: An investigation of employee intentions to support organizational change, The Journal of Applied Behavioral Science, vol. 44, no. 2, pp. 237-62.

Kim, C., Mirusmonov, M., \& Lee, I., (2010a), An empirical examination of factors influencing the intention to use mobile payment, Computers in Human Behavior, vol. 26, no. 3, pp. 310-22.

Kim, C., Tao, W., Shin, N., \& Kim, K.-S., (2010b), An empirical study of customers' perceptions of security and trust in e-payment systems, Electronic Commerce Research and Applications, vol. 9, no. 1, pp. 84-95.

Krueger, N. F., Reilly, M. D., \& Carsrud, A. L., (2000), Competing models of entrepreneurial intentions, Journal of Business Venturing, vol. 15, no. 5, pp. 411-32.

Lee, M.-C., (2009), Factors influencing the adoption of internet banking: An integration of TAM and TPB with perceived risk and perceived benefit, Electronic Commerce Research and Applications, vol. 8, no. 3, pp. 130-41.

Legoh'erel, P., Dauc'e, B., Hsu, C. H. C., \& Ranchhold, A., (2009), Culture, Time Orientation, and Exploratory Buying Behavior, Journal of International Consumer Marketing, vol. 21, pp. 93-107.

Liébana-Cabanillas, F. J., Sánchez-Fernández, J., \& Muñoz-Leiva, F., (2014), Antecedents of the adoption of the new mobile payment systems: The moderating effect of age, Computers in Human Behavior, vol. 35, pp. 464-78.

Lizin, S., Van Dael, M., \& Van Passel, S., (2017), Battery pack recycling: Behaviour change interventions derived from an integrative theory of planned behaviour study, Resources, Conservation and Recycling, vol. 122, pp. 66-82.

Manavipour, D., \& Saeedian, Y., (2016), The role of self-compassion and control belief about learning in university students' self-efficacy, Journal of Contextual Behavioral Science, vol. 5, no. 2, pp. 121-26. 
Mansori, S., Sambasivan, M., \& Md-Sidin, S., (2015 ), Acceptance of novel products: the role of religiosity, ethnicity and values, Marketing Intelligence \& Planning, vol. 33, no. 1, pp. 39-66.

Memon, M. A., Ting, H., Ramayah, T., Chuah, F., \& Cheah, J. H., (2017), A review of the methodological misconceptions and guidelines related to the application of structural equation modelling: A Malaysian scenario, Journal of Applied Structural Equation Modeling, vol. 1, no. 1, pp. i-xiii.

Minton, E. A., Spielmann, N., Kahle, L. R., \& Kim, C. H., (2018), The subjective norms of sustainable consumption: A cross-cultural exploration, Journal of Business Research, vol. 82, pp. 400-08.

Misra, S., \& Wickamasinghe, N., (2004), Security of a mobile transaction: A trust model, Electronic Commerce Research, vol. 4, no. 4, pp. 359-72.

Norazah Mohd, S., \& Norbayah Mohd, S., (2011), User' behaviour towards ubiquitos Mlearning, The Turkish Online Journal of Distance Education, vol. 12, no. 3, pp. 11829.

Ondrus, J., \& Pigneur, Y., (2006), Towards a holistic analysis of mobile payments: A multiple perspectives approach, Electronic Commerce Research and Applications, vol. 5, no. 3, pp. 246-57.

Pires, G., \& Stanton, J., (2000), Marketing services to ethnic consumers in culturally diverse markets: issues and implications, Journal of Services Marketing, vol. 14, no. 7, pp. 607-18.

Podsakoff, P. M., MacKenzie, S. B., Lee, J. Y. Y., \& Podsakoff, N. P., (2003), Common method biases in behavioral research: A critical review of the literature and recommended remedies, Journal of Applied Psychology, vol. 88, no. 5, pp. 879-903.

Qin, L., Kim, Y., \& Tan, X., (2018), Understanding the intention of using mobile social networking apps across cultures, International Journal of Human-Computer Interaction, vol. 34 , no. 12 , pp. 1183-93.

Ramayah, T., Cheah, J. H., Chuah F., Ting, H., \& Memon, M. A., (2018), Partial least squares structural equation modeling (PLS-SEM) using SmartPLS 3.0: An updated and practical guide to statistical analysis, 2nd ed., Pearson Limited.

Renzetti, C. M., \& Curran, D. J., (1998), Living Sociology, Allyn and Bacon.

Rivis, A., \& Sheeran, P., (2003), Descriptive norms as an additional predictor in the theory of planned behaviour: A meta-analysis, A Journal for Diverse Perspectives on Diverse Psychological Issues, vol. 22, no. 3, pp. 218-33.

Schwartz, S. H., (1999), A theory of cultural values and some implications for work, Applied Psychology: An International Review, vol. 48, no. 1, pp. 23-47.

Shin, D. H., (2010), Modeling the interaction of users and mobile payment system: Conceptual framework, International Journal of Human-Computer Interaction, vol. 26, no. 10, pp. 917-40.

Siau, K., Sheng, H., Nah, F., \& Davis, S., (2004), A qualitative investigation on consumer trust in mobile commerce, International Journal of Electronic Business, vol. 2, no. 3.

Statista. (2019), "Mobile POS payments", Retrieved from https://www.statista.com/

Stevenson, J., Bruner, G., \& Kumar, A., (2000), Webpage background and viewer attitudes, Journal of Advertising Research, vol. 40, no. 1/2, pp. 29-34.

Suki, N., \& Ramayah, T., (2010), User acceptance of the e-government services in Malaysia: Structural equation modelling approach, Interdisciplinary Journal of Information, vol. 5, pp. 395-413.

Sulaiman, A., Jaafar, N. I., \& Mohezar, S., (2007), An overview of mobile banking adoption among the urban community, International Journal of Mobile Communications, vol. 5, no. 2, pp. 157-68.

Tariq, J., Sajjad, A., Usman, A., \& Amjad, A., (2017), The role of intentions in facebook usage among educated youth in Pakistan: An extension of the theory of planned behavior, Computers in Human Behavior, vol. 74, pp. 188-95.

The Star Online, (2014), "Bank Negara: Use online payment and mobile banking", Retrieved from www.thestart.com.my 
The Star Online, (2015), "Good news for Internet users", Retrieved from www.thestar.com.my

Ting, H., Lim, T. Y., de Run, E. C., Koh, H., \& Sahdan, M., (2018), Are we Baby Boomers, Gen $\mathrm{X}$ and Gen Y? A qualitative inquiry into generation cohorts in Malaysia, Kasetsart Journal of Social Sciences, vol. 39, no. 1, pp. 109-15.

Ting, H., Yacob, Y., Liew, L., \& Lau, W. M., (2016), Intention to use mobile payment system: A case of developing market by ethnicity, Procedia - Social and Behavioral Sciences, vol. 224, pp. 368-75.

Usunier, J. C., (2005), Marketing across cultures, 4th ed., Prentice Hall.

Venkatesh, M., \& Davis, T., (2003), User acceptance of information technology: Toward a unified view, MIS Quarterly, vol. 27, no. 3, pp. 425.

Wang, Y., Sun, S., Lei, W., \& Toncar, M., (2009), Examining beliefs and attitudes toward online advertising among chinese consumers, Direct Marketing: An International Journal, vol. 3, no. 1, pp. 52-66.

Weir, C. S., Anderson, J. N., \& Jack, M. A., (2006), On the role of metaphor and language in design of third party payments in eBanking: Usability and quality, International Journal of Human - Computer Studies, vol. 64, no. 8, pp. 770-84.

Wong, E. L., (2017), "70\% of Malaysians ready to adopt mobile payments, says Visa", Retrieved from http://www.theedgemarkets.com

Ye, S., Soutar, G. N., Sneddon, J. N., \& Lee, J. A., (2017), Personal values and the theory of planned behaviour: A study of values and holiday trade-offs in young adults, Tourism Management, vol. 62, pp. 107-09. 